\title{
Changes in serum aldosterone are associated with changes in obesity-related factors in normotensive overweight and obese young adults
}

\author{
Jennifer N Cooper ${ }^{1,2}$, Linda Fried ${ }^{1,3}$, Ping Tepper ${ }^{1}$, Emma Barinas-Mitchell ${ }^{1}$, Molly B Conroy ${ }^{1,4}$, \\ Rhobert W Evans ${ }^{1}$, Maria Mori Brooks ${ }^{1,2}$, Genevieve A Woodard ${ }^{1}$ and Kim Sutton-Tyrrell ${ }^{1}$
}

Recent data suggest excess circulating aldosterone promotes cardiometabolic decline. Weight loss may lower aldosterone levels, but little longitudinal data is available in normotensive adults. We aimed to determine whether, independent of changes in sodium excretion, reductions in serum aldosterone are associated with favorable changes in obesity-related factors in normotensive overweight/obese young adults. We studied 285 overweight/obese young adult participants (body mass index $\geqslant 25$ and $<40 \mathrm{~kg} \mathrm{~m}^{-2}$, age 20-45 years) in a clinical trial examining the effects of a 1-year diet and physical activity intervention with or without sodium restriction on vascular health. Body weight, serum aldosterone, 24-h sodium and potassium excretion and obesity-related factors were measured at baseline, 6, 12 and 24 months. Weight loss was significant at 6 (7\%), 12 (6\%) and 24 months (4\%; all $\boldsymbol{P}<0.0001$ ). Decreases in aldosterone were associated with decreases in $\mathrm{C}$-reactive protein, leptin, insulin, homeostasis assessment of insulin resistance, heart rate, tonic cardiac sympathovagal balance and increases in adiponectin (all $\boldsymbol{P}<0.05$ ) in models adjusting for baseline age, sex, race, intervention arm, time since baseline, and sodium and potassium excretion. Weight loss and reductions in thigh intermuscular fat (intermuscular adipose tissue area; IMAT) were associated with decreases in aldosterone in the subgroup $(n=98)$ with metabolic syndrome (MetS) at baseline (MetS $\times$ weight loss, $\boldsymbol{P}=0.04$; MetS $\times$ change in IMAT, $\boldsymbol{P}=0.04$ ). Favorable changes in obesity-related factors are associated with reductions in aldosterone in young adults with no risk factors besides excess weight, an important finding, given aldosterone's emergence as an important cardiometabolic risk factor.

Hypertension Research (2013) 36, 895-901; doi:10.1038/hr.2013.45; published online 9 May 2013

Keywords: adipokines; adipose tissue; aldosterone; metabolic syndrome; obesity

\section{INTRODUCTION}

Aldosterone has important roles in blood pressure (BP) regulation and sodium and water balance, but inappropriately elevated levels have been found to promote cardiovascular decline ${ }^{1}$ and are also associated with obesity-related metabolic abnormalities. ${ }^{2-6}$ Furthermore, several studies have found that aldosterone levels are higher in overweight/obese individuals, particularly those with excess visceral fat. $^{2-5}$ Aldosterone was found to decrease with modest weight loss when individuals reduced their calorie intake while maintaining a low, moderate or high dietary sodium intake. ${ }^{5,7-10}$

These findings may be partially explained by adipose tissue production of renin-angiotensin-aldosterone system (RAAS) components. ${ }^{11-13}$ Human adipocytes also produce mineralocorticoidstimulating factors that increase adrenal aldosterone secretion independently of angiotensin II (Ang II) or potassium. ${ }^{14}$ Another mechanism for RAAS overactivition in overweight/obese individuals is impaired renal sympathovagal balance, which stimulates renin release by the kidneys. ${ }^{11}$ Furthermore, both renal and cardiac sympathovagal balance are worsened by excess circulating aldosterone. ${ }^{15}$ Finally, increased formation of Ang II by large insulin-resistant adipocytes inhibits the recruitment and differentiation of preadipocytes, which leads to ectopic fat storage and decreased insulin sensitivity. ${ }^{16}$ Altogether, this evidence suggests the presence of a vicious cycle wherein excess adiposity promotes aldosterone production and excess aldosterone, along with other RAAS components, drives adipose inflammation, insulin resistance and cardiovascular decline.

Although several studies have reported decreases in aldosterone with weight loss, ${ }^{5,7-10}$ no study of healthy normotensive young adults has examined associations between changes in aldosterone and changes in obesity-related factors while accounting for changes in sodium intake, an important determinant of circulating aldosterone

${ }^{1}$ Department of Epidemiology, Graduate School of Public Health, University of Pittsburgh, Pittsburgh, PA, USA; 2Department of Biostatistics, Graduate School of Public Health, University of Pittsburgh, Pittsburgh, PA, USA; ${ }^{3}$ VA Pittsburgh Healthcare System, University Drive Division, Pittsburgh, PA, USA and ${ }^{4}$ Division of General Internal Medicine, University of Pittsburgh, Pittsburgh, PA, USA

Correspondence: Dr JN Cooper, Department of Epidemiology, Epidemiology Data Center, Graduate School of Public Health, University of Pittsburgh, 130 DeSoto St, Pittsburgh, PA 15261, USA. 
levels. We hypothesized that, independent of changes in 24-h sodium excretion, reductions in serum aldosterone would be associated with weight loss and reductions in regional adiposity, thigh intermuscular adiposity, inflammation, leptin, insulin resistance and sympathovagal balance, and increases in adiponectin and ghrelin in normotensive overweight/obese young adults followed over the course of a 1-year lifestyle intervention and 1-year post-intervention period. We also hypothesized that, independent of weight loss, decreases in both serum aldosterone and sodium excretion would be associated with decreases in BP. Finally, because individuals with greater metabolic dysfunction may be more sensitive to the cardiovascular and metabolic effects of excess aldosterone and dietary sodium, ${ }^{17}$ we hypothesized that individuals with metabolic syndrome (MetS) would show stronger associations between the factors of interest.

\section{METHODS}

\section{Study population}

Subjects came from the slow adverse vascular effects of excess weight study (SAVE), a randomized-controlled trial (NCT00366990) evaluating the effects of weight loss, increased physical activity and reduced dietary sodium intake on vascular health. Participants were recruited during June 2007-May 2009 using mass mailing. The study was approved by the University of Pittsburgh institutional review board, and all participants provided written informed consent.

Eligible participants were men and women $20-45$ years of age who were overweight/obese (body mass index (BMI) $25-39.9 \mathrm{~kg} \mathrm{~m}^{-2}$ ) and physically inactive ( $<8$ months of physical activity during the past 12 months). Exclusions included (1) diabetes, (2) hypertension or average screening $\mathrm{BP} \geqslant 140 / 90 \mathrm{~mm} \mathrm{Hg}$, (3) cholesterol lowering, antipsychotic, or vasoactive medication use and (4) current pregnancy or lactation. Three hundred and forty-nine eligible participants received a 1-year lifestyle intervention promoting diet and physical activity (PA). Participants were randomized either to (1) diet and physical activity alone (control $\mathrm{Na} /$ lifestyle) or to (2) diet and physical activity plus reduced sodium intake (low Na/lifestyle). The lifestyle intervention was delivered in group sessions that occurred weekly for months $1-4$, biweekly for months $5-8$ and monthly for months $9-12$. The goal of the intervention was $10 \%$ weight loss over 6 months and continued weight maintenance thereafter. The goal of the sodium reduction intervention (low $\mathrm{Na}$ ) was to gradually reduce sodium intake to $\sim 1 \mathrm{mg} \mathrm{Na}$ per kcal per day. Participants were to be seen at screening, baseline, and 6,12 and 24 months following randomization.

\section{Demographic and physical measures}

Age, race and smoking status were self-reported. Race was re-coded as black vs non-black. Smoking status was assessed as current vs past or never. Weight was measured in kilograms using a balance scale. Height was measured in centimeters using a stadiometer. Waist circumference was measured against the participant's skin at the narrowest part of the torso between the ribs and the iliac crest. BP was measured with a mercury sphygmomanometer after participants sat quietly for $5 \mathrm{~min}$ with feet flat on the floor. Final BP was the average of the last two of three readings taken $30 \mathrm{~s}$ apart.

\section{Blood and urine assays}

Blood analytes were measured at the Heinz Laboratory at the University of Pittsburgh's Graduate School of Public Health using standard methods, as previously described. ${ }^{18,19}$ Briefly, blood specimens were obtained between 0700 and $1130 \mathrm{~h}$ from upright subjects after a fasting period of at least $9 \mathrm{~h}$. Serum aldosterone was measured using an enzyme-linked immunoassay developed by Diagnostic Systems Laboratories (Webster, TX, USA). The intra- and inter-assay coefficient of variation percentage for insulin were $4.8 \%$ and $10.5 \%$ respectively. The coefficient of variation percentage for the other assays were all $<3 \%$.

Twenty-four-hour urine collections were performed within 2 weeks of the clinic visits at which all other measurements were determined. Valid collections had volume between 500 and $4000 \mathrm{ml}$, duration $\geqslant 22$ and $\leqslant 26 \mathrm{~h}$ and creatinine within the expected range. ${ }^{20}$ Sodium, potassium and creatinine were determined as previously described. ${ }^{18}$

\section{Regional measures of adiposity}

At baseline and 12 months, single-slice computed tomography scans of the abdomen and thigh were acquired using a C-150 Ultrafast computed tomography Scanner (GE Imatron, San Francisco, CA, USA). Slice thickness was $6 \mathrm{~mm}$. Abdominal scans were transverse images between L4 and L5 lumbar vertebrae obtained during suspended respiration; left thigh images were transverse images $15 \mathrm{~cm}$ above the patellar apex.

Computed tomography images were interpreted by one reader (MBC) using Slice-O-Matic software (TomoVision, Magog, QC, Canada). A pixel range of -30 to -190 Hounsfield units was used to define fat in the scan circumference. Areas were calculated by multiplying the number of pixels of a given tissue type by the pixel area. Density values were determined by averaging the computed tomography number (pixel density) values of the regions outlined on the images. For the abdominal scan, region of interest lines were drawn along fascial planes. Fat above the internal fascial plane was considered subcutaneous fat and fat below the plane was considered visceral fat area. For the thigh scan, a single region of interest line was drawn along the deep fascial plane surrounding the thigh muscle. Fat above this line was considered subcutaneous fat and fat below was considered intermuscular fat. ${ }^{21}$

\section{Heart rate variability}

At baseline and 6 months, an ANSAR monitor (ANX-3.0, ANSAR Group, Philadelphia, PA, USA) provided continuous and noninvasive measurements of electrocardiogram signals (for heart rate variability assessment) and bioimpedance plethysmography signals (for respiratory rate variability assessment).22 A spectral analysis of the heart rate variability and respiratory rate variability was generated using ANSAR software. The low-frequency area was centered on the heart rate variability spectrum from 0.04 to $0.10 \mathrm{~Hz}$, which is taken to reflect sympathetic cardiac activity. From the spectral analysis of the respiratory rate variability, the frequency of the peak mode was defined as the fundamental respiratory frequency. A $0.12-\mathrm{Hz}$ wide window from the heart rate variability spectrum was centered at the fundamental respiratory frequency and used to generate the respiratory frequency area, which is taken to reflect parasympathetic cardiac activity. ${ }^{23}$ The area under the spectral curve centered on the fundamental respiratory frequency is computed as respiratory frequency area. The remaining area under the spectral curve in the low-frequency bandwidth is computed as low-frequency area. The measure examined in this analysis was low-frequency area/respiratory frequency area during an initial 5-min resting period (tonic sympathovagal balance).

\section{Statistical methods}

Whether changes in variables of interest were statistically significant was determined by testing the coefficient for time in linear-mixed models with unstructured error covariance. Intervention arm was included as a covariate for consistency with trial design. An interaction between intervention arm and time was used to test whether changes differed by intervention arm.

The main analysis began with linear-mixed models with aldosterone as the time-varying dependent variable, measured at baseline and 6, 12 and 24 months. Independent variables were age, sex, race, baseline and withinsubject changes in sodium and potassium excretion, and baseline and withinsubject changes in obesity-related variables of interest. The following obesityrelated variables were individually evaluated: BMI, weight, waist circumference, abdominal visceral and subcutaneous adipose tissue areas, thigh intermuscular adipose tissue area (IMAT), insulin, homeostasis model assessment of insulin resistance, adiponectin, leptin, ghrelin, C-reactive protein, resting supine heart rate and sitting low-frequency area/respiratory frequency area (cardiac sympathovagal balance). A fixed quadratic time effect and random intercepts, and linear and quadratic time effects were evaluated and included if found to be significant at $P<0.10$. To determine whether associations varied over time or across subgroups of interest, interactions between changes in the obesityrelated factors and time, race, sex, age or the presence of $\mathrm{MetS}^{24}$ at baseline 
were tested. To evaluate whether associations between aldosterone and non-anthropometric obesity-related factors were independent of weight loss and changes in insulin levels, baseline and within-subject changes in BMI, weight, waist circumference or fasting insulin were added to the models.

Linear-mixed models for systolic blood pressure and diastolic blood pressure were used to assess whether changes in urinary sodium excretion or serum aldosterone were associated with BP changes independent of weight loss, adjusting for baseline age, sex, race, weight, and baseline and within-subject changes in potassium excretion. Interactions between changes in sodium excretion and baseline serum aldosterone, race, sex, age and MetS status were evaluated. Finally, both in the models for aldosterone and the models for BP, each component of the MetS $S^{25}$ was investigated individually in place of overall MetS status, using a Bonferroni correction for multiple comparisons.

Sensitivity analyses were performed to evaluate potential effects of the missing data. First, sodium/creatinine and potassium/creatinine excretion ratios were used in place of 24-h sodium and potassium excretion in order to include data from all urine collections rather than only completely valid collections. Second, to examine the hypothesis that participants with missing follow-up data were on average less successful in achieving weight loss than participants with complete data, pattern-mixture modeling and multiple imputation were used. Multiple imputation was performed for each missing data pattern under the assumption that the multivariate distribution of the missing data for each pattern, given the observed data, followed the corresponding distribution in those subjects with complete data who had achieved less than the mean weight loss at follow-up visits with unavailable data for that pattern. $P$-values $\leqslant 0.05$ were considered statistically significant. Statistical analyses were performed using SAS (Statistical Analysis Software v9.3, SAS Institute, Cary, NC, USA).

\section{RESULTS}

The study population consisted of 285 participants in the SAVE trial who provided valid baseline 24-h urine collections and serum aldosterone data. The sample had a mean age of 38.4 years (s.d. 5.8) at baseline. Twenty percent of participants were male and $15 \%$ black. In addition, $8 \%$ self-identified as current smokers. Mean values of key clinical characteristics over the course of the intervention are shown in Table 1. Average weight loss was $7.1 \%$ at 6 months, $6.4 \%$ at 12 months and $3.5 \%$ at 24 months.

The only measures that differed at least marginally by intervention arm were changes in sodium excretion and serum aldosterone. Mean sodium excretion was decreased from baseline by $48.1 \mathrm{mmol}$ per $24 \mathrm{~h}$ (s.d. 79.7) at 6 months, $35.0 \mathrm{mmol}$ per $24 \mathrm{~h}$ (s.d. 80.5) at 12 months and $42.0 \mathrm{mmol}$ per $24 \mathrm{~h}$ (s.d. 75.8 ) at 24 months in the low $\mathrm{Na} /$ lifestyle arm, but decreased by only $9.1 \mathrm{mmol}$ per $24 \mathrm{~h}$ (s.d. 77.1) at 6 months, $20.5 \mathrm{mmol}$ per $24 \mathrm{~h}$ (s.d. 84.8 ) at 12 months and $7.6 \mathrm{mmol}$ per $24 \mathrm{~h}$ (s.d. 78.2) at 24 months in the control Na/lifestyle arm $(P<0.001, P=0.27$ and $P=0.01$, respectively, for between-arm comparisons). Serum aldosterone was marginally higher in the low $\mathrm{Na}$ /lifestyle arm compared with the control $\mathrm{Na} /$ lifestyle arm at 6 months only $(P=0.06)$.

Changes in weight, BMI, waist circumference and abdominal adiposity were not associated with changes in aldosterone in multivariable mixed models for log aldosterone, although there was a marginal association between decreased thigh IMAT and decreased aldosterone (Table 2). Changes in circulating adipokines and markers of insulin resistance, inflammation and tonic cardiac sympathovagal

Table 1 Clinical characteristics across the 1-year intervention and at 1-year post-intervention

\begin{tabular}{|c|c|c|c|c|}
\hline Characteristic & Baseline $(n=285)$ & 6 months $(\mathrm{n}=233)$ & 12 months $(\mathrm{n}=210)$ & 24 months $(\mathrm{n}=189)$ \\
\hline Aldosterone (pg ml-1) & $108(79,156)$ & $117(84.3,156)$ & $104(84,140)$ & $107(83.1,157.5)$ \\
\hline Weight (kg) & $91.8(13.3)$ & $84.6(13.3)^{*}$ & $85.1(14.2)^{*}$ & $88.1(14.6)^{*}$ \\
\hline $\mathrm{BMI}\left(\mathrm{kg} \mathrm{m}^{-2}\right)$ & $32.9(3.7)$ & $30.3(4.1)^{*}$ & $30.4(4.4)^{*}$ & $31.4(4.5)^{*}$ \\
\hline Waist circumference $(\mathrm{cm})$ & $100.1(10.3)$ & $94.8(10.7)^{*}$ & $95.0(11.8)^{*}$ & $97.5(12.3)^{*}$ \\
\hline $\mathrm{SBP}(\mathrm{mm} \mathrm{Hg})$ & $113.2(10.1)$ & $109.5(9.0)^{*}$ & $109.7(9.6)^{*}$ & $112.2(9.9)$ \\
\hline $\mathrm{DBP}(\mathrm{mm} \mathrm{Hg})$ & $72.7(8.5)$ & $70.6(8.2)^{*}$ & $71.7(7.8)$ & $73.8(9.1)^{*}$ \\
\hline Glucose (mg dl-1) & $97.3(7.9)$ & $97.8(8.4)$ & $98.2(8.3)$ & $97.6(9.5)$ \\
\hline Insulin $\left(\mu \cup \mathrm{ml}^{-1}\right)$ & $12.5(9.4,16.7)$ & $11.4(8.7,15.4)^{*}$ & $11.8(9.3,15.3)$ & $11.9(9.5,15.4)$ \\
\hline HOMA-IR $\left(\mathrm{mmolI}^{-1} \times \mu \mathrm{U} \mathrm{ml}^{-1}\right)$ & $3.0(2.2,4.2)$ & $2.7(2.1,3.8)^{*}$ & $2.9(2.2,4.0)$ & $2.9(2.2,3.8)$ \\
\hline LDL-C (mg dl-1) & $123.2(32.8)$ & $121.4(29.1)$ & $123.3(30.8)$ & $125.5(32.6)$ \\
\hline $\mathrm{HDL}-\mathrm{C}\left(\mathrm{mg} \mathrm{dl}^{-1}\right)$ & $52.5(12.7)$ & $52.8(12.1)$ & $55.5(13.7)^{*}$ & $54.5(13.3)^{*}$ \\
\hline Triglycerides (mg dl ${ }^{-1}$ ) & $115.5(79,169.5)$ & $94(67,135)^{*}$ & $88(71,136)^{*}$ & $99(75,146)^{*}$ \\
\hline CRP $\left(\mathrm{mg}^{-1}\right)$ & $2.6(1.4,5.6)$ & $2.2(1.0,4.6)^{*}$ & $2.1(0.94,4.2)^{*}$ & $2.3(0.91,5.0)^{*}$ \\
\hline Leptin (ng ml-1) & $26.2(13.1)$ & $18.6(11.5)^{*}$ & $21.0(13.5)^{*}$ & $22.7(13.4)^{*}$ \\
\hline Adiponectin $\left(\mu \mathrm{g} \mathrm{ml}^{-1}\right)$ & $11.9(6.1)$ & $12.1(5.6)^{*}$ & $12.1(5.7)$ & $10.6(5.7)^{*}$ \\
\hline Ghrelin (pg ml-1) & $673.5(547,874.5)$ & $774(614,1042)^{*}$ & $804.5(629,1121.5)^{*}$ & $875(711,1113)^{*}$ \\
\hline Sodium excretion (mmol per $24 \mathrm{~h})^{\mathrm{a}}$ & $185.8(69.1)$ & $154.5(65.2)^{*}$ & $156.9(58.9)^{*}$ & $157.6(63.5)^{*}$ \\
\hline Potassium excretion (mmol per $24 \mathrm{~h})^{\mathrm{a}}$ & $60.7(22.1)$ & $62.0(21.0)$ & $63.9(23.1)$ & $61.6(21.3)$ \\
\hline Heart rate (beats per min) & $64.3(9.2)$ & $62.7(8.4)^{*}$ & $64.0(8.9)$ & $63.6(8.8)$ \\
\hline Sitting cardiac sympathovagal balance ${ }^{\mathrm{b}}$ & $1.6(0.87,2.9)$ & $1.1(0.64,2.6)^{*}$ & - & - \\
\hline Abdominal visceral fat area $\left(\mathrm{cm}^{2}\right)^{c}$ & $117.8(56.0)$ & - & $99.1(53.5)^{*}$ & - \\
\hline Abdominal subcutaneous fat area $\left(\mathrm{cm}^{2}\right)^{\mathrm{c}}$ & $425.0(122.4)$ & - & $361.0(132.2)^{*}$ & - \\
\hline Thigh intermuscular fat area $\left(\mathrm{cm}^{2}\right)^{\mathrm{c}}$ & $13.0(4.8)$ & - & $7.7(3.7)^{*}$ & - \\
\hline
\end{tabular}

Abbreviations: BMI, body mass index; CRP, C-reactive protein; DBP, diastolic blood pressure; HDL-C, high-density lipoprotein cholesterol; HOMA-IR, homeostasis model assessment of insulin resistance; LDL-C, low-density lipoprotein cholesterol; LFa, low-frequency area, RFa, respiratory frequency area; SBP, systolic blood pressure. Mean (s.d.) or median (IQR) are shown.

Aldosterone, insulin, HOMA-IR, triglycerides, CRP, ghrelin and sitting cardiac sympathovagal balance were log transformed for modeling.

To convert to SI units, use the following conversion factors: glucose, 0.0555; insulin, 6.945; LDL-C and HDL-C, 0.0259; triglycerides, 0.0113; CRP, 9.524; leptin, 0.0625; ghrelin, 0.296; aldosterone, 2.774

${ }^{*} P<0.05$ versus baseline in a linear-mixed model with time since baseline as a nominal variable and with adjustment for intervention arm.

a $P$ aseline $n=285,6$ months $n=184,12$ months $n=158,24$ months $n=136$.

baseline $n=277,6$ months $n=227$.

cBaseline $n=272,12$ months $n=200$. 
Table 2 Associations between changes in serum aldosterone and changes in obesity-related factors over the course of the study

\begin{tabular}{|c|c|c|}
\hline $\begin{array}{l}\text { Independent variable } \\
\text { (change from baseline) }\end{array}$ & $\begin{array}{c}\text { Percent change in aldosterone associated } \\
\text { with one-unit change in independent variable } \\
\qquad(95 \% \mathrm{Cl})\end{array}$ & $\mathrm{P}$-value \\
\hline \multicolumn{3}{|l|}{ Anthropometric measures } \\
\hline Weight (\%) & $0.029(-0.50,0.56)$ & 0.92 \\
\hline $\mathrm{BMI}\left(\mathrm{kgm}^{-2}\right)$ & $-0.007(-1.60,1.61)$ & 0.99 \\
\hline $\begin{array}{l}\text { Waist circumference } \\
(\mathrm{cm})\end{array}$ & $0.12(-0.45,0.69)$ & 0.69 \\
\hline \multicolumn{3}{|l|}{ Serum measures } \\
\hline Insulin $\left(\mu \cup \mathrm{ml}^{-1}\right)$ & $1.41(0.64,2.19)$ & 0.0005 \\
\hline $\mathrm{CRP}\left(\left.\mathrm{mg}\right|^{-1}\right)$ & $2.33(1.11,3.56)$ & 0.0002 \\
\hline Leptin $\left(n g \mathrm{ml}^{-1}\right)$ & $0.62(0.21,1.04)$ & 0.003 \\
\hline Adiponectin ( $\mu \mathrm{g} \mathrm{ml}^{-1}$ ) & $-1.98(-3.01,-0.94)$ & 0.0002 \\
\hline Ghrelin $\left(p g \mathrm{ml}^{-1}\right)$ & $0.004(-0.01,0.01)$ & 0.42 \\
\hline \multicolumn{3}{|l|}{ Cardiac measures } \\
\hline $\begin{array}{l}\text { Heart rate (beats per } \\
\text { min) }\end{array}$ & $0.91(0.36,1.47)$ & 0.001 \\
\hline $\begin{array}{l}\text { Log sitting cardiac } \\
\text { sympathovagal balance }\end{array}$ & $11.40(5.04,18.15)$ & 0.0004 \\
\hline \multicolumn{3}{|l|}{ CT adiposity measures } \\
\hline $\begin{array}{l}\text { Abdominal visceral fat } \\
\text { area }\left(\mathrm{cm}^{2}\right)\end{array}$ & $0.12(-0.10,0.34)$ & 0.28 \\
\hline $\begin{array}{l}\text { Abdominal subcuta- } \\
\text { neous fat area }\left(\mathrm{cm}^{2}\right)\end{array}$ & $0.04(-0.04,0.12)$ & 0.29 \\
\hline $\begin{array}{l}\text { Thigh intermuscular fat } \\
\text { area }\left(\mathrm{cm}^{2}\right)\end{array}$ & $2.22(-0.15,4.66)$ & 0.053 \\
\hline
\end{tabular}

Abbreviations: BMI, body mass index; $\mathrm{Cl}$, confidence interval; CRP, C-reactive protein; $\mathrm{CT}$, computed tomography; HOMA-IR, homeostasis model assessment of insulin resistance. The association with HOMA-IR $(P=0.02)$ was similar to the association with fasting insulin and thus is not shown. Percentage changes in aldosterone for a one-unit change in the independent variable were calculated using the formula $100 \times(\exp (\beta)-1)$, where $\beta$ was the parameter estimate for the independent variable from the mixed model.

To convert to SI units, use the following conversion factors: insulin, 6.945; CRP, 9.524; leptin 0.0625 ; ghrelin, 0.296 .

${ }^{a} P$-values are from linear-mixed models for log aldosterone $\left(\mathrm{pg} \mathrm{ml}^{-1}\right)$ that included baseline age, sex, race (black/non-black), intervention arm, time since baseline, and baseline and within-subject changes in 24-h urinary sodium and potassium excretion, and baseline and within-subject changes in the specified independent variable.

balance were strongly associated with changes in aldosterone. As expected, there were at least marginal associations between increases in aldosterone, and both decreases in sodium excretion and increases in potassium excretion in all models $(P<0.10$ for all, data not shown).

Weight loss (Figure 1a) and BMI reduction were associated with reduced aldosterone in the subgroup $(n=98,34 \%)$ with MetS at baseline $(P<0.05$ for both interactions). However, interactions between MetS and changes in waist circumference or abdominal adipose tissue depots were not significant $(P>0.10$ for all), although decreased thigh IMAT was associated with decreased aldosterone in the subgroup with MetS (Figure 1b). When each MetS component was investigated individually in the models for aldosterone, no component showed a significant interaction with changes in obesity-related factors or sodium or potassium excretion. The associations between changes in aldosterone and changes in all nonanthropometric obesity-related factors were unaltered by additional adjustment for baseline and within-subject changes in weight, BMI, waist circumference, fasting insulin or homeostasis model assessment of insulin resistance (data not shown).
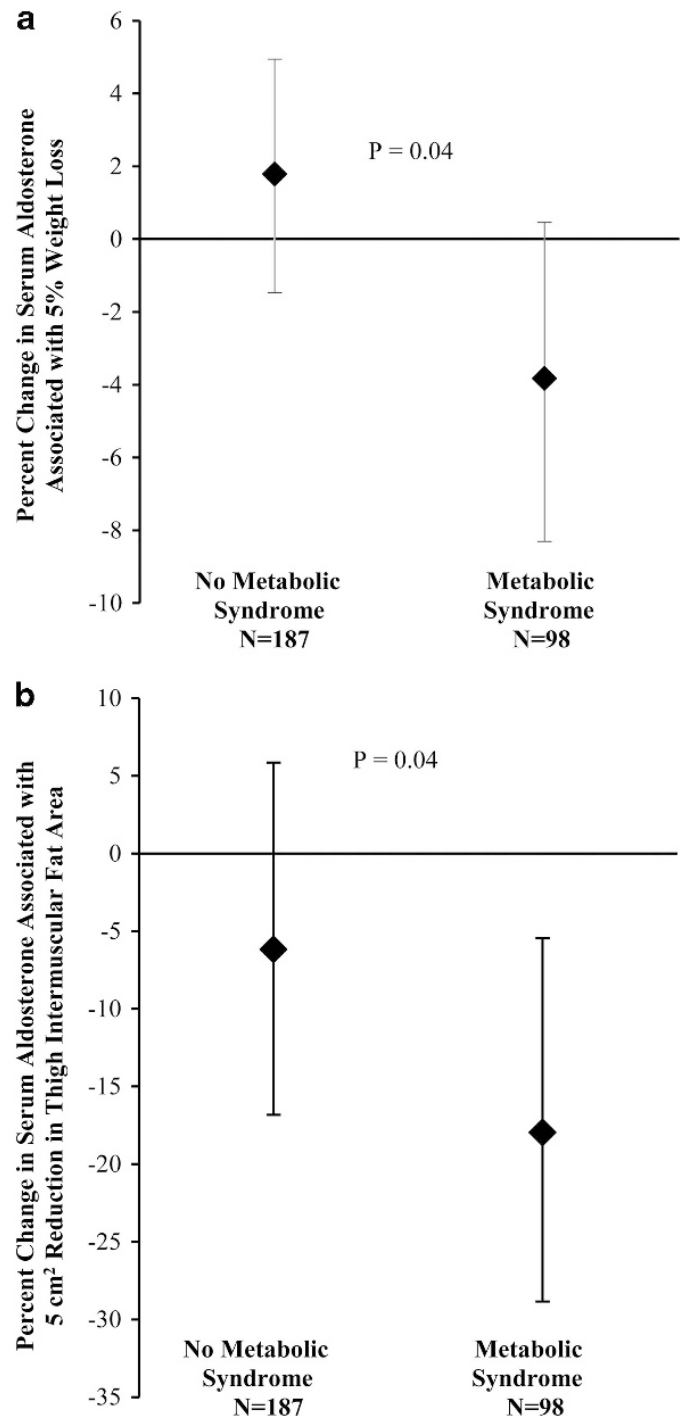

Figure 1 Change in serum aldosterone associated with (a) $5 \%$ weight loss and (b) $5 \mathrm{~cm}^{2}$ reduction in thigh intermuscular fat area: differences by baseline metabolic syndrome (MetS) status. Parameter estimates and 95\% confidence intervals shown are from a linear-mixed effects model for log aldosterone that included baseline age, sex, race (black/non-black), weight, intervention arm, time since baseline, baseline and within-subject changes in 24-h urinary sodium and potassium excretion, percent weight reduction (or change in thigh intermuscular fat area), baseline MetS status and the interaction between percent weight reduction (or change in thigh intermuscular fat area) and baseline MetS status. The $P$-value shown is for the interaction.

Neither changes in sodium excretion nor changes in aldosterone were associated with changes in BP (Table 3). However, the association between reduced sodium excretion and reduced diastolic blood pressure was marginally greater in subjects who had MetS at baseline or who were of black race (Figures 2 and 3). These interactions were not significant for systolic blood pressure $(P>0.20$ for both). Again, no significant interactions were detected between individual MetS components and changes in sodium excretion (data not shown).

In sensitivity analyses, when sodium/creatinine and potassium/ creatinine excretion ratios were used in place of 24 -h sodium and potassium excretion, 55 additional subjects were included. However, the associations of interest were similar to those from the original models (data not shown). Results from pattern-mixture modeling, 
Table 3 Associations between changes in blood pressure and changes in weight, serum aldosterone and urinary electrolytes over the course of the study

\begin{tabular}{|c|c|c|c|}
\hline Independent variable & $\begin{array}{l}\text { Parameter } \\
\text { estimate }\end{array}$ & s.e. & P-value \\
\hline \multicolumn{4}{|l|}{ Diastolic blood pressure } \\
\hline Weight loss (\%) & 0.20 & 0.045 & $<0.0001$ \\
\hline $\begin{array}{l}\text { Change in sodium excretion ( } \mathrm{mmol} \text { per } \\
24 \mathrm{~h} \text { ) }\end{array}$ & 0.0075 & 0.0047 & 0.11 \\
\hline $\begin{array}{l}\text { Change in potassium excretion ( } \mathrm{mmol} \text { per } \\
24 \mathrm{~h} \text { ) }\end{array}$ & -0.0059 & 0.016 & 0.72 \\
\hline Change in log aldosterone (pg ml-1) & -0.35 & 0.67 & 0.60 \\
\hline \multicolumn{4}{|l|}{ Systolic blood pressure } \\
\hline Weight loss (\%) & 0.28 & 0.047 & $<0.0001$ \\
\hline $\begin{array}{l}\text { Change in sodium excretion ( } \mathrm{mmol} \text { per } \\
24 \mathrm{~h} \text { ) }\end{array}$ & 0.0031 & 0.0049 & 0.52 \\
\hline $\begin{array}{l}\text { Change in potassium excretion ( } \mathrm{mmol} \text { per } \\
24 \mathrm{~h} \text { ) }\end{array}$ & -0.013 & 0.017 & 0.45 \\
\hline Change in log aldosterone (pg ml-1) & -0.85 & 0.70 & 0.23 \\
\hline
\end{tabular}

a $P$-values are from linear-mixed models for each respective blood pressure measure that included baseline age, sex, race (black/non-black), intervention arm, time since baseline, baseline weight, percent weight loss, and baseline and within-subject changes in serum aldosterone and 24-h urinary sodium and potassium excretion.

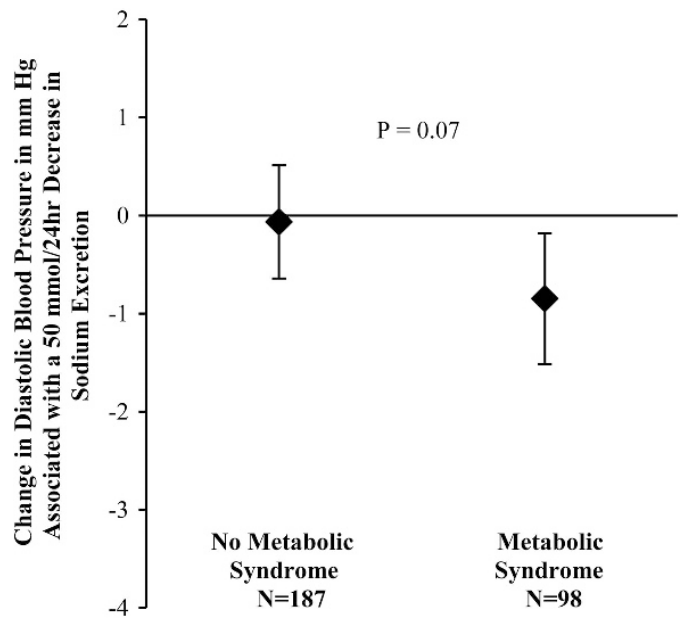

Figure 2 Change in diastolic blood pressure (DBP) associated with a $50-\mathrm{mmol}$ per $24 \mathrm{~h}$ decrease in sodium excretion: differences by baseline metabolic syndrome (MetS) status. Parameter estimates and $95 \%$ confidence intervals shown are from a linear-mixed effects model for DBP that included baseline age, sex, race (black/non-black), weight, intervention arm, time since baseline, baseline and within-subject changes in urinary sodium and potassium excretion and serum aldosterone, percent weight reduction, baseline MetS status, and the interaction between change in sodium excretion and baseline MetS status. The $P$-value shown is for the interaction between change in sodium excretion and baseline MetS status in this model. A decrease in sodium excretion of $50 \mathrm{mmol}$ per $24 \mathrm{~h}$ was approximately the median decrease from baseline to 24 months in the low $\mathrm{Na} /$ lifestyle intervention arm.

with missing follow-up data multiply imputed, also differed little from those in the original mixed models, although most associations were slightly weaker under the assumption of less successful weight loss among dropouts than completers (Supplementary Information).

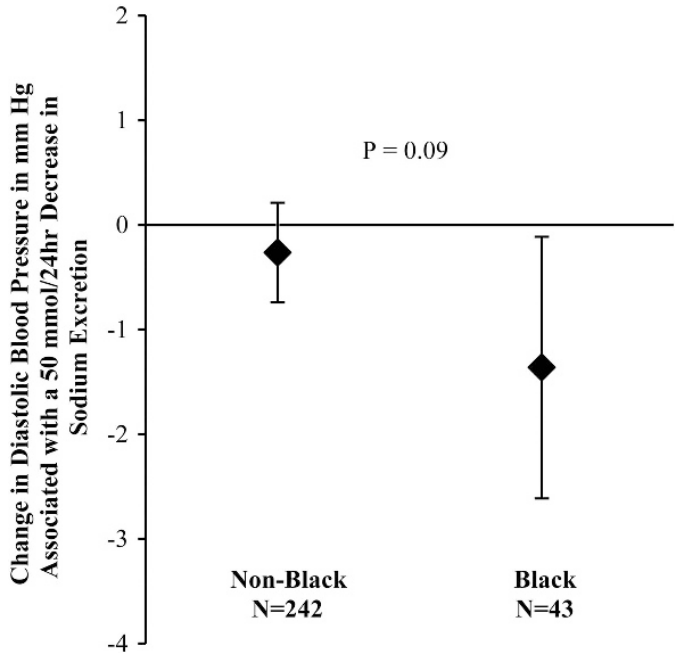

Figure 3 Change in diastolic blood pressure (DBP) associated with a 50-mmol per $24 \mathrm{~h}$ decrease in sodium excretion: differences by race. Parameter estimates and $95 \%$ confidence intervals shown are from a linear-mixed effects model for DBP that included baseline age, sex, race (black/non-black), weight, intervention arm, time since baseline, baseline and within-subject changes in urinary sodium and potassium excretion and serum aldosterone, percent weight reduction, and the interaction between change in sodium excretion and race. The $P$-value shown is for the interaction between change in sodium excretion and race in this model. A decrease in urinary sodium excretion of $50 \mathrm{mmol}$ per $24 \mathrm{~h}$ was approximately the median decrease from baseline to 24 months in the low $\mathrm{Na}$ /lifestyle intervention arm.

\section{DISCUSSION}

The main findings of this study were that, independent of changes in sodium excretion, decreases in serum aldosterone were associated with reductions in fasting insulin, homeostasis model assessment of insulin resistance, C-reactive protein, leptin, heart rate, and cardiac sympathovagal balance and increases in adiponectin in normotensive overweight/obese young adults during a 1-year lifestyle intervention and 1-year post-intervention period. In addition, although changes in weight and aldosterone were unassociated in the total sample, such an association was evident in the subgroup with MetS at baseline. Finally, decreased intermuscular thigh fat was marginally associated with decreased aldosterone in the total sample and significantly associated with decreased aldosterone in the subgroup with MetS at baseline. These findings are important because this is the first study in a large sample of overweight/obese otherwise healthy young adults to report associations between changes in circulating aldosterone and changes in a wide variety of obesity-related factors during and following a behavioral weight loss intervention.

Previous, small or moderate-sized studies have reported decreases in serum aldosterone or aldosterone excretion with modest weight loss in obese postmenopausal women, ${ }^{8}$ young overweight/obese adults, $^{5,7}$ middle-aged overweight/obese adults ${ }^{9,26}$ and obese adults who submitted to very low calorie diets. ${ }^{5,10}$ Some studies have reported significant associations between reductions in circulating RAAS components and reductions in central adiposity 5 or insulin resistance ${ }^{5}$ during weight loss, although not all studies agree to this report. ${ }^{7}$ Potential reasons for discrepant findings between studies include different levels of sodium intake and heterogeneous study populations. Unlike the present study, no past studies consisted of only normotensives, evaluated the effect of weight loss on aldosterone independent of changes in discretionary sodium intake, followed participants after weight loss or examined as many obesityrelated factors. 
The present findings are particularly important, given the emergence of aldosterone as a cardiometabolic risk factor, promoting not only hypertension, but also inflammation and remodeling of the heart, vasculature, kidneys and adipose tissue. ${ }^{27}$ Higher levels of circulating aldosterone predict incident hypertension ${ }^{28}$ and $\mathrm{MetS}^{6}$ in the general population. Furthermore, this study and several others have found that higher aldosterone levels correlate with greater insulin resistance, 3,5 an association that may be independent of anthropometric measures of body size. ${ }^{3}$ Thus, it appears that aldosterone may influence cardiometabolic health independently of $\mathrm{BMI}$ and other traditional risk factors.

A likely explanation for the stronger associations of circulating aldosterone with markers of metabolic dysfunction than with anthropometric measures of body size or abdominal adipose tissue area is that it is the quality rather than the quantity of adipose tissue that determines cardiometabolic dysfunction. ${ }^{11,29}$ 'Dysfunctional' adipose tissue is characterized by hypertrophied adipocytes, increased macrophage infiltration, hypoxia, and marked changes in adipokine and free fatty acid secretion. ${ }^{29,30}$ Elevated production of leptin, angiotensinogen and reduced production of adiponectin accompany the accumulation of dysfunctional fat. ${ }^{29}$ In addition, as excess energy intake overwhelms the body's fat storage capacity, ectopic fat is stored in skeletal muscle and the liver. ${ }^{29}$ These changes promote insulin resistance, chronic systemic inflammation, RAAS activation, sympathoactivation and oxidative stress. ${ }^{29}$ In obese individuals with metabolic dysfunction, both visceral and subcutaneous adipose tissue depots are characterized by increased proinflammatory macrophage content and adipocyte hypertrophy. ${ }^{31}$ These morphological changes are not necessarily accompanied by significant changes in the amount of total body fat or visceral or subcutaneous fat mass, ${ }^{31}$ but they are linked to intrahepatic and intramuscular fat storage, which promote metabolic abnormalities. ${ }^{21}$ To our knowledge, this is the first study to report associations between serum aldosterone and intermuscular fat.

Although it is impossible in this study to determine which obesityrelated factors most influenced serum aldosterone or which factors were most influenced by serum aldosterone, it is likely that all of the investigated factors are both causes and consequences of cardiometabolic decline. ${ }^{32}$ Adipocytes produce angiotensinogen and Ang II contributing to elevated circulating levels of these hormones in obese individuals. ${ }^{33,34}$ Although there is argument that human adipocytes do not produce aldosterone, ${ }^{12}$ a recent study suggests otherwise. ${ }^{13}$ In addition, it was recently discovered that several adipocyte-derived factors increase adrenal aldosterone production independent of Ang II and serum potassium. ${ }^{14,35,36}$ Type 1 and 2 adiponectin receptors are also present in the adrenal cortex, and may influence aldosterone secretion. $^{37}$ Furthermore, increased aldosterone secretion by adrenocortical cells results in greater binding and activation of adipocyte mineralocorticoid receptors, which in turn impacts adipose differentiation, expansion and inflammation. ${ }^{32}$ Finally, there is evidence that both circulating and adipose RAAS are influenced by autonomic activity. Sympathetic nerve stimulation increases the release of renin and Ang II and the stimulatory effect of Ang II on adrenal aldosterone secretion. ${ }^{38}$ Elevated circulating aldosterone also induces cardiac and renal sympathetic activation. ${ }^{15}$ Although associations between reductions in weight and BP were evident in this study, changes in aldosterone and sodium were not associated with changes in BP. It may be that chronically elevated aldosterone increases BP over longer time periods, such as the 4 years, over which persons were followed in a study that found aldosterone to predict incident hypertension. ${ }^{28}$ In addition, the effect of weight loss may have overwhelmed the effects of concurrent changes in sodium and aldosterone. However, the associations between reductions in sodium excretion and reductions in BP in individuals of black race or who had MetS agree with past studies, ${ }^{39,40}$ and suggest that these subgroups may particularly benefit from sodium reduction along with weight loss to reduce BP.

\section{Limitations and strengths}

There were several limitations to this study. As the focus of this study was not a comparison of the randomized treatment arms, it was not possible to determine causal relationships. However, the longitudinal design of this study did minimize the influence of time-independent confounders. Another limitation was the $<10 \%$ mean weight loss achieved by study subjects. This smaller than expected weight loss may have limited our ability to detect associations of interest. Small numbers of males and non-whites provided insufficient power to stratify these analyses by sex or race. In addition, there is some evidence that aldosterone levels may differ by sex and race; $;^{41}$ thus the use of a heterogeneous sample that included 20\% male and 15\% black subjects may have diluted our findings. In addition, aldosterone levels vary throughout the menstrual cycle. Importantly however, we found no statistically significant interactions with sex or race in the models for serum aldosterone, suggesting that the associations between aldosterone and obesity-related factors did not differ by sex or race. Another limitation was that the lack of data on other RAAS components and natriuretic peptides prevented us from examining the extent to which changes in these factors contributed to the detected associations. However, the evidence that excess adiposity directly stimulates mineralocorticoid secretion ${ }^{14,35,36}$ suggests that renin and other established drivers of aldosterone secretion may not fully explain the associations detected in this study. Furthermore, hypertension and the use of antihypertensives, the most common stimuli for high levels or changes in renin release, were not present in any study subjects, and in all analyses we adjusted for baseline levels and changes in sodium excretion a major stimulus of the RAAS. It could be that a measure of 24-h aldosterone excretion might have reflected chronic circulating aldosterone exposure more accurately than a serum measurement. Another limitation was the missing data; however sensitivity analyses suggested that the findings were robust and likely not biased by the missing data. A strength of this study was that no participants were using antihypertensive or vasoactive medications, thus eliminating treatment-related confounding. Finally, the large variety of measured obesity-related factors and the longitudinal design of this study provided novel insights into the complex role of aldosterone in cardiometabolic health during and after lifestyle modification.

\section{CONCLUSIONS}

In conclusion, in normotensive, overweight/obese young adults followed over the course of a 1-year lifestyle intervention and 1-year follow-up period, reductions in fasting insulin, homeostasis model assessment of insulin resistance, C-reactive protein, leptin, heart rate, tonic cardiac sympathovagal balance and increases in adiponectin are associated with decreases in serum aldosterone. In addition, 5\% weight loss is associated with a $4 \%$ reduction in serum aldosterone, and a reduction in intermuscular fat of $5 \mathrm{~cm}^{2}$ is associated with an $18 \%$ reduction in serum aldosterone in individuals with MetS. These findings, along with recent studies showing that mineralocorticoid receptor antagonists improve adipose tissue function in animal models of obesity, ${ }^{42}$ suggest that future trials should test the efficacy of these drugs for reducing cardiometabolic risk in overweight/obese 
individuals, particularly in those with metabolic abnormalities. Of course, positive lifestyle changes must continue to be recommended to all persons with excess weight, as even modest weight loss can improve cardiometabolic health.

\section{CONFLICT OF INTEREST}

The authors declare no conflict of interest.

\section{ACKNOWLEDGEMENTS}

This work was supported by Grants R01 HL077525 and F31 HL106986 from the National Heart, Lung, and Blood Institute of the National Institutes of Health. We thank Beth Hauth for expert laboratory analyses. We greatly appreciate the efforts of the SAVE trial volunteers and the study and clinic coordinators (Laura Kinzel and Eileen Cole).

1 Nehme J, Mercier N, Labat C, Benetos A, Safar ME, Delcayre C, Lacolley P. Differences between cardiac and arterial fibrosis and stiffness in aldosterone-salt rats: effect of eplerenone. J Renin Angiotensin Aldosterone Syst 2006; 7: 31-39.

2 Rossi GP, Belfiore A, Bernini G, Fabris B, Caridi G, Ferri C, Giacchetti G, Letizia C, Maccario M, Mannelli M, Palumbo G, Patalano A, Rizzoni D, Rossi E, Pessina AC, Mantero F. Body mass index predicts plasma aldosterone concentrations in overweightobese primary hypertensive patients. J Clin Endocrinol Metab 2008; 93: 2566-2571.

3 Bentley-Lewis R, Adler GK, Perlstein T, Seely EW, Hopkins PN, Williams GH, Garg R. Body mass index predicts aldosterone production in normotensive adults on a high-salt diet. J Clin Endocrinol Metab 2007; 92: 4472-4475.

4 Goodfriend TL, Egan BM, Kelley DE. Plasma aldosterone, plasma lipoproteins, obesity and insulin resistance in humans. Prostaglandins Leukot Essent Fatty Acids 1999; 60: 401-405.

5 Goodfriend TL, Kelley DE, Goodpaster BH, Winters SJ. Visceral obesity and insulin resistance are associated with plasma aldosterone levels in women. Obes Res 1999; 7: 355-362.

6 Ingelsson E, Pencina MJ, Tofler GH, Benjamin EJ, Lanier KJ, Jacques PF, Fox CS, Meigs JB, Levy D, Larson MG, Selhub J, D'Agostino RB Sr., Wang TJ, Vasan RS. Multimarker approach to evaluate the incidence of the metabolic syndrome and longitudinal changes in metabolic risk factors: the Framingham Offspring Study. Circulation 2007; 116: 984-992.

7 Harp JB, Henry SA, DiGirolamo M. Dietary weight loss decreases serum angiotensinconverting enzyme activity in obese adults. Obes Res 2002; 10: 985-990.

8 Engeli S, Bohnke J, Gorzelniak K, Janke J, Schling P, Bader M, Luft FC, Sharma AM Weight loss and the renin-angiotensin-aldosterone system. Hypertension 2005; 45 356-362.

9 Fogari R, Zoppi A, Corradi L, Preti P, Mugellini A, Lazzari P, Derosa G. Effect of body weight loss and normalization on blood pressure in overweight non-obese patients with stage 1 hypertension. Hypertens Res 2010; 33: 236-242.

10 Tuck ML, Sowers J, Dornfeld L, Kledzik G, Maxwell M. The effect of weight reduction on blood pressure, plasma renin activity, and plasma aldosterone levels in obese patients. N Engl J Med 1981; 304: 930-933.

11 Dorresteijn JA, Visseren FL, Spiering W. Mechanisms linking obesity to hypertension. Obes Rev 2011; 13: 17-26.

12 MacKenzie SM, Huda SS, Sattar N, Fraser R, Connell JM, Davies E. Depot-specific steroidogenic gene transcription in human adipose tissue. Clin Endocrinol (Oxf) 2008; 69: 848-854

13 Briones AM, Cat AN, Callera GE, Yogi A, Burger D, He Y, Correa JW, Gagnon AM, Gomez-Sanchez CE, Gomez-Sanchez EP, Sorisky A, Ooi TC, Ruzicka M, Burns KD, Touyz RM. Adipocytes produce aldosterone through calcineurin-dependent signaling pathways: implications in diabetes mellitus-associated obesity and vascular dysfunction. Hypertension 2012; 59: 1069-1078.

14 Ehrhart-Bornstein M, Lamounier-Zepter V, Schraven A, Langenbach J, Willenberg HS, Barthel A, Hauner H, McCann SM, Scherbaum WA, Bornstein SR. Human adipocytes secrete mineralocorticoid-releasing factors. Proc Natl Acad Sci USA 2003; 100 $14211-14216$

15 Zhang ZH, Yu Y, Wei SG, Felder RB. Aldosterone-induced brain MAPK signaling and sympathetic excitation are angiotensin II type-1 receptor dependent. Am J Physiol Heart Circ Physiol 2012; 302: H742-H751.

16 Furuhashi M, Ura N, Takizawa H, Yoshida D, Moniwa N, Murakami H, Higashiura K, Shimamoto K. Blockade of the renin-angiotensin system decreases adipocyte size with improvement in insulin sensitivity. J Hypertens 2004; 22: 1977-1982.
17 Rocchini AP, Key J, Bondie D, Chico R, Moorehead C, Katch V, Martin M. The effect of weight loss on the sensitivity of blood pressure to sodium in obese adolescents. $N$ Engl J Med 1989; 321: 580-585.

18 Cooper JN, Tepper P, Barinas-Mitchell E, Woodard GA, Sutton-Tyrrell K. Serum aldosterone is associated with inflammation and aortic stiffness in normotensive overweight and obese young adults. Clin Exp Hypertens 2012; 34: 63-70.

19 Njoroge JN, El Khoudary SR, Fried LF, Barinas-Mitchell E, Sutton-Tyrrell K. High urinary sodium is associated with increased carotid intima-media thickness in normotensive overweight and obese adults. Am J Hypertens 2011; 24: 70-76.

20 Ellis D, Lloyd C, Becker DJ, Forrest KYZ, Orchard TJ. The changing course of diabetic nephropathy: low-density lipoprotein cholesterol and blood pressure correlate with regression of proteinuria. Am J Kidney Dis 1996; 27: 809-818.

21 Goodpaster BH, Krishnaswami S, Harris TB, Katsiaras A, Kritchevsky SB, Simonsick EM, Nevitt M, Holvoet $P$, Newman AB. Obesity, regional body fat distribution, and the metabolic syndrome in older men and women. Arch Intern Med 2005; 165: 777-783.

22 Colombo J, Shoemaker WC, Belzberg H, Hatzakis G, Fathizadeh P, Demetriades D. Noninvasive monitoring of the autonomic nervous system and hemodynamics of patients with blunt and penetrating trauma. J Trauma 2008; 65: 1364-1373.

23 Aysin B, Aysin E. Effect of respiration in heart rate variability (HRV) analysis. Conf Proc IEEE Eng Med Biol Soc 2006; 1: 1776-1779.

24 Grundy SM, Cleeman JI, Daniels SR, Donato KA, Eckel RH, Franklin BA, Gordon DJ, Krauss RM, Savage PJ, Smith SC, Spertus JA, Costa F. Diagnosis and management of the metabolic syndrome. Circulation 2005; 112: 2735-2752.

25 Grundy SM. Metabolic syndrome scientific statement by the American Heart Association and the National Heart, Lung, and Blood Institute. Arterioscler Thromb Vasc Biol 2005; 25: 2243-2244.

26 Ho JT, Keogh JB, Bornstein SR, Ehrhart-Bornstein M, Lewis JG, Clifton PM, Torpy DJ. Moderate weight loss reduces renin and aldosterone but does not influence basal or stimulated pituitary-adrenal axis function. Horm Metab Res 2007; 39: 694-699.

27 Zennaro MC, Caprio M, Feve B. Mineralocorticoid receptors in the metabolic syndrome. Trends Endocrinol Metab 2009; 20: 444-451.

28 Vasan RS, Evans JC, Larson MG, Wilson PWF, Meigs JB, Rifai N, Benjamin EJ, Levy D. Serum aldosterone and the incidence of hypertension in nonhypertensive persons. N Engl J Med 2004; 351: 33-41.

29 Pausova Z. From big fat cells to high blood pressure: a pathway to obesity-associated hypertension. Curr Opin Nephrol Hypertens 2006; 15: 173-178.

30 Hajer GR, van Haeften TW, Visseren FL. Adipose tissue dysfunction in obesity, diabetes, and vascular diseases. Eur Heart J 2008; 29: 2959-2971.

31 Srdic B, Stokic E, Korac A, Ukropina M, Velickovic K, Breberina M. Morphological characteristics of abdominal adipose tissue in normal-weight and obese women of different metabolic profiles. Exp Clin Endocrinol Diabetes 2010; 118: 713-718.

32 Marzolla V, Armani A, Zennaro MC, Cinti F, Mammi C, Fabbri A, Rosano GM, Caprio M. The role of the mineralocorticoid receptor in adipocyte biology and fat metabolism. Mol Cell Endocrinol 2012; 350: 281-288.

33 Yasue S, Masuzaki H, Okada S, Ishii T, Kozuka C, Tanaka T, Fujikura J, Ebihara K, Hosoda K, Katsurada A, Ohashi N, Urushihara M, Kobori H, Morimoto N, Kawazoe T, Naitoh M, Okada M, Sakaue H, Suzuki S, Nakao K. Adipose tissue-specific regulation of angiotensinogen in obese humans and mice: impact of nutritional status and adipocyte hypertrophy. Am J Hypertens 2010; 23: 425-431.

34 Harte A, McTernan P, Chetty R, Coppack S, Katz J, Smith S, Kumar S. Insulinmediated upregulation of the renin angiotensin system in human subcutaneous adipocytes is reduced by rosiglitazone. Circulation 2005; 111: 1954-1961.

35 Jeon JH, Kim KY, Kim JH, Baek A, Cho H, Lee YH, Kim JW, Kim D, Han SH, Lim JS, Kim KI, Yoon do Y, Kim SH, Oh GT, Kim E, Yang Y. A novel adipokine CTRP1 stimulates aldosterone production. FASEB J 2008; 22: 1502-1511.

36 Goodfriend TL, Ball DL, Egan BM, Campbell WB, Nithipatikom K. Epoxy-keto derivative of linoleic acid stimulates aldosterone secretion. Hypertension 2004; 43: 358-363.

37 Rossi GP, Sticchi D, Giuliani L, Bernante P, Zavattiero S, Pessina AC, Nussdorfer GG Adiponectin receptor expression in the human adrenal cortex and aldosteroneproducing adenomas. Int J Mol Med 2006; 17: 975-980.

38 Kalil GZ, Haynes WG. Sympathetic nervous system in obesity-related hypertension: mechanisms and clinical implications. Hypertens Res 2012; 35: 4-16.

39 Chen J, Gu D, Huang J, Rao DC, Jaquish CE, Hixson JE, Chen CS, Lu F, Hu D, Rice T, Kelly TN, Hamm LL, Whelton PK, He J. Metabolic syndrome and salt sensitivity of blood pressure in non-diabetic people in China: a dietary intervention study. Lancet 2009; 373: 829-835.

40 Swift PA, Markandu ND, Sagnella GA, He FJ, MacGregor GA. Modest salt reduction reduces blood pressure and urine protein excretion in black hypertensives: a randomized control trial. Hypertension 2005; 46: 308-312.

41 Montori VM, Schwartz GL, Chapman AB, Boerwinkle E, Turner ST. Validity of the aldosterone-renin ratio used to screen for primary aldosteronism. Mayo Clin Proc 2001; 76: 877-882.

42 Hirata A, Maeda N, Hiuge A, Hibuse T, Fujita K, Okada T, Kihara S, Funahashi T, Shimomura I. Blockade of mineralocorticoid receptor reverses adipocyte dysfunction and insulin resistance in obese mice. Cardiovasc Res 2009; 84: 164-172.

Supplementary Information accompanies the paper on Hypertension Research website (http://www.nature.com/hr) 